www.jmscr.igmpublication.org

Impact Factor 5.84

Index Copernicus Value: 83.27

ISSN (e)-2347-176x ISSN (p) 2455-0450

crossref DOI: https://dx.doi.org/10.18535/jmscr/v5i2.10

Journal Of Medical Science And Clinical Research

IGM Publication

An official Publication of IGM Publication

\title{
A Study of Clonidine and Dexmedetomidine as Adjuvant to Epidural Levobupivacaine for Post Operative Analgesia in Infraumbilical Surgeries
}

\author{
Authors \\ Dr Narayan Acharya ${ }^{1}$, Dr Daityari Routray ${ }^{2}$ \\ ${ }^{1}$ Assoc Prof, Department of Anaesthesiology, MKCG Medical College, Berhampur, Odisha \\ ${ }^{2}$ Prof, Department of Anaesthesiology, MKCG Medical College, Berhampur, Odisha \\ Corresponding Author \\ Dr Narayan Acharya.Assoc Prof \\ Department of Anaesthesiology, MKCG Medical College, Berhampur, Odisha \\ Email: drnarayan2017@gmail.com, Mobileno-7008115431
}

\begin{abstract}
Background: Epidural analgesia with adjuvant is the popular method for intra and postoperative pain relief but search for ideal adjuvant for prolonging the duration of postoperative analgesia without any side effect goes on.

Aim: This study was conducted to study the onset, extent and duration of sensory and motor block and side effects of clonidine or dexmedetomidine when used as an adjuvant in epidural levobupivacaine.

Materials and Methods: 80 patients of ASA status I and II, posted for infraumbilical surgery were randomly allocated into two groups of 40 each. Group I group patients received $18 \mathrm{ml}$ of $0.5 \%$ levobupivacaine and clonidine $2 \mathrm{mcg} / \mathrm{kg}$ in epidural route and Group II group patients received $18 \mathrm{ml}$ of $0.5 \%$ levobupivacaine and dexmedetomidine $1.5 \mathrm{mcg} / \mathrm{kg}$ in epidural route. Itraoperative and postoperative block characteristics as well as hemodynamic parameters were observed and recorded.

Results: Dexmedetomidine had an earlier onset and longer duration of sensory and motor block in comparison to clonidine. Sedation scores were statistically significant with dexmedetomidine group in comparison to clonidine group.

Conclusion: Dexmedetomidine was a better than clonidine as an adjuvant to levobupivacaine in epidural anaesthesia in total knee replacement.

Keywords- clonidine, dexmedetomidine, levobupivacaine, total knee replacement.
\end{abstract}

\section{Introduction}

Epidural anaesthesia provides both intra and post operative pain relief in various infraumbilical surgeries. Epidural bupivacaine had been used commonly in the past for providing post-operative pain relief in patients undergoing lower limb surgeries. ${ }^{[1]}$. Neuraxial anaesthesia and analgesia provide potent analgesic effect by inhibiting nociceptive transmission from peripheral to central neuronal system, but their analgesic effect may be limited by the short half life of current local anaesthetics. The analgesic duration can be prolonged by increasing dose of local anaesthetics; however the risk of accompanied systemic toxicity can be increased ${ }^{[2]}$. Therefore, adjuvant can be added to local anaesthetics to prolong the analgesic duration and to limit the dose requirement of local anaesthetics. Recently, 
several neuraxial adjuvants, including clonidine, fentanyl, dexamethasone, ketamine, magnesium sulphate and midazolam have demonstrated the synergistic analgesic effect with local anaesthetics with varying degrees of success. But the search for ideal adjuvant for a particular local anaesthetic goes on $^{[3]}$. Recemic bupivacaine is most frequently used long acting local anaesthetic agent. But the low dose bupivacaine is often used in order to reduce cardiovascular side effects which may not provide an adequate anaesthesia for surgery ${ }^{[4]}$. Nowadays ropivacaine has replaced bupivacaine for the same reason but it is shorter acting than levobupivacaine. Levobupivacaine is the isolated S (-) isomer of bupivacaine. Due to lower affinity of S(-) isomer to cardiac sodium channel compared to $\mathrm{R}$ isomer, it is less cardio toxic ${ }^{[5]}$. So we have chosen levobupivacaine as the local anaesthetic because it is longer acting and devoid of cardiac side effects.

Literature is available using $\alpha-2$ agonists like clonidine and dexmedetimidine as adjuvant to local anaesthetics like bupivacaine and ropivacaine in epidural route but very few are there regarding their use with levobupivacaine. $\alpha$ 2 adrenergic agonists like clonidine and dexemedetomidine have both analgesic and sedative properties when used as an adjuvant in regional anaesthesia ${ }^{[6]}$. Dexmedetomidine has an eight-fold greater affinity for $\alpha_{2}$ adrenergic receptors than clonidine and much less $\alpha 1$ activity. Its higher selectivity $\alpha_{2 \mathrm{~A}}$ receptors are responsible for the hypnotic and analgesic effects ${ }^{[7]}$. Previous studies have shown that clonidine and dexemedetomidine improved the quality of block when used as adjuvant with ropivacaine or bupivacaine in epidural block but studies are limited where levobupivacaine is used as local anaesthetic.

This study was designed to compare the analgesic, sedative action and side effects of dexmedetomidine and clonidine when added to levobupivacaine for epidural analgesia in patients undergoing total knee replacement.

\section{Material and Methods}

Ethical committee approval and written informed consent were obtained from 80 ASA status (I / II) patients of ages 25-65 years posted for infraumbilical surgeries.

Patients with history of coagulopathy, uncontrolled hypertension, cardiac, respiratory, hepatic, neurological, neuromuscular disease; with allergy to the used drugs, contraindication or failure of epidural anaesthesia were excluded from the study.

ECG, pulse oximetry $\left(\mathrm{SPO}_{2}\right)$ and non-invasive blood pressure (NIBP) were monitored.

After infusion of $500 \mathrm{ml}$ of lactated Ringer's solution, patients were put in the sitting position. 3 $\mathrm{ml}$ of lidocaine $2 \%$ was used to infiltrate the skin and subcutaneous tissues.

A 17 gauge tuohy epidural needle was used at L3L4 space. After loss of resistance, the epidural catheter was advanced 3-4 cm into the epidural space. Patients with any evidence of needle or catheter entry into an epidural vein or into the CSF were excluded from this study. A test dose of $3 \mathrm{ml}$ or $2 \%$ lignocaine solution containing adrenaline 1: 200,000 was injected. After 4-6 min of injecting the test dose and excluding intravascular or subarachnoid injection, patiens were allocated to one of two groups in double blinded fashion based on computer generated code. Group I: levobupivacaine and clonidine in which $18 \mathrm{ml}$ of $0.5 \%$ levobupivacaine and clonidine $2 \mu \mathrm{g} / \mathrm{kg}$ was administered in the epidural catheter. Group II: levobupivacaine and dexmedetomidine in which $18 \mathrm{ml}$ of $0.5 \%$ levobupivacaine and $1.5 \mu \mathrm{g} / \mathrm{kg}$ dexmedetomidine was administered in the epidural catheter. The drug syringes were prepared by an anaesthetist who was blind about the study. Sensory block was assessed using the blunt end of a 27-gauge needle. Motor blockade was assessed by using the modified bromage scale (bromage 0: The patient is able to move the hip, knee and ankle; bromage 1: the patient is unable raise extended leg; bromage 2: The patient is unable to move the hip and knee but able to move the ankle; bromage 3: The patient is unable to move the hip, knee and 
ankle). The time to reach the peak sensory level and bromage 3 motor blocks were recorded before surgery. The regression time for sensory and motor block were recorded in post anaesthesia care unit. All durations were calculated from the time of epidural injection.

The two groups were monitored pre and intraoperatively for heart rate, non-invasive blood pressure and $\mathrm{O}_{2}$ saturation $\left(\mathrm{SpO}_{2}\right)$. Hypotension was defined as systolic blood pressure $<90 \mathrm{mmHg}$ or $>30 \%$ decrease in baseline values and was treated by fluids and vasopressors.

Tachycardia was defined as heart rate $>100 / \mathrm{min}$. Bradycardia was defined as heart rate $<55 / \mathrm{min}$ and was treated by inj $0.6 \mathrm{mg}$ atropine. Intraoperative nausea, vomiting, pruritus, sedation or any other side effects were recorded.

Sedation was assessed by sedation score (1: alert and awake, 2: arousable to verbal command, 3: arousable with gentle tactile stimulation, 4: arousable with vigorous shaking. 5: unarousable).

\section{Statistical Methods}

Data were presented as mean \pm SD. $t$-test was used to compare the two groups for quantitative data and chi-square test was used for qualitative data by SPSS V18. Value of $\mathrm{p}<0.05$ was considered statistically significant.

\section{Results}

A total of 80 patients posted for infraumbilical surgery were enrolled for the study. They were randomly divided into two groups. The demographic profiles of the patients in both the groups were comparable with regards to age, sex, height, weight and body mass index. The ASA status of patients was similar in both the groups and mean duration of surgery was comparable in both the groups. $(\mathrm{p}>0.05)$ [Table 1].

Onset of sensory block at $\mathrm{T} 10$ level was earlier in group II $(7.24 \pm 2.55 \mathrm{~min})$ compared to the group I (8.45 $\pm 2.64 \mathrm{~min})$. Higher dermatomal spread (T67) was seen in group II in comparison to group I(T7-8). Time for maximum sensory level was shorter $(11.2 \pm 3.45 \mathrm{~min})$ in group II compared to group I (15.8 $\pm 3.84 \mathrm{~min})$. All the above sensory block characteristics were statistically significant in group II in comparison to group I. Complete motor block was achieved earlier $(16.25 \pm 6.7 \mathrm{~min})$ in group II and 19.5 \pm 5.7 min in group I which was statistically significant. $(\mathrm{p}<0.05)$. [Table 2].

Many previous studies had shown that dexmedetomidine can be used as intraoperative sedative agent. In our study mean sedation scores were significantly higher in group II compared to group I which is statistically significant. [Table 3]. Mean time to 2 segmental dermatomal regression was $146.46 \pm 8.5 \mathrm{~min}$ and $135.5 \pm 9.8 \mathrm{~min}$ in group II and I respectively. Return of motor power to bromage 1 was $251.22 \pm 38.26 \mathrm{~min}$ in Igroup and $284.52 \pm 25.44 \mathrm{~min}$ in group II. Both the block characteristics were statistically significant. The time for rescue analgesia was comparatively shorter $(319.18 \pm 24.81 \mathrm{~min})$ in the group I and $355.66 \pm 25.8 \mathrm{~min}$ in group II which was statistically significant. $(\mathrm{P}<0.05)$. [Table 4]. The Cardio-respiratory parameters like heart rate, mean arterial pressure, spo 2 and respiratory rate were stable and more or less similar in both the groups throughout the study period.

Table 5 showed the comparative incidence of various side effects in both the groups which were statistically not significant. We did not observe respiratory depression in any patient in both the group. 


\section{JMSCR Vol||05||Issue||02||Pages 17292-17298||February}

Table 1- Demographic profile of patients of both group.

\begin{tabular}{|l|c|c|c|}
\hline Demographic characteristics & $\begin{array}{c}\text { LCgroup }(\mathrm{n}=40) \\
\text { Mean } \pm \text { SD }\end{array}$ & $\begin{array}{c}\text { LD group }(\mathrm{n}=40) \\
\text { Mean } \pm \text { SD }\end{array}$ & P value \\
\hline Age $(\mathrm{yrs})$ & $45.5 \pm 10.6$ & $47.9 \pm 9.4$ & 0.36 \\
\hline Sex $(\mathrm{m}: \mathrm{f})$ & $20: 10$ & $18: 12$ & 0.79 \\
\hline Weight $(\mathrm{kg})$ & $60.82 \pm 10.45$ & $62.42 \pm 8.94$ & 0.53 \\
\hline Height $(\mathrm{cm})$ & $150.4 \pm 8.25$ & $152.65 \pm 8.4$ & 0.30 \\
\hline BMI $\left(\mathrm{Kg} / \mathrm{m}^{2}\right)$ & $27.6 \pm 2.95$ & $28.46 \pm 3.22$ & 0.28 \\
\hline ASA $(\mathrm{I} / \mathrm{II})$ & $25 / 5$ & $26 / 4$ & 1.0 \\
\hline Mean duration of surgery $(\mathrm{min})$ & $90.45 \pm 15.1$ & $94.21 \pm 14.35$ & 0.33 \\
\hline
\end{tabular}

Table 2 - Comparison of preoperative block characteristics

\begin{tabular}{|l|c|c|c|}
\hline Block characteristics & LC group $(\mathrm{n}=40)$ & LD group $(\mathrm{n}=40)$ & $\mathrm{P}$ Value \\
\hline $\begin{array}{l}\text { Onset time of sensory block at } \mathrm{T} \\
10(\text { mins) }\end{array}$ & $8.45 \pm 2.64$ & $7.24 \pm 2.55$ & 0.0235 \\
\hline Max sensory block level & T7-T8 & T6-T7 & 0.05 \\
\hline Time to max sensory block(mins) & $15.8 \pm 3.84$ & $11.2 \pm 3.45$ & 0.001 \\
\hline Time for complete motor block(mins) & $19.5 \pm 5.7$ & $16.25 \pm 6.7$ & 0.02 \\
\hline Total ephedrine requirement (mg) & $7.85 \pm 2.1$ & $7.5 \pm 1.8$ & 0.11 \\
\hline
\end{tabular}

Table -3 Sedation score in both group

\begin{tabular}{|l|c|c|c|}
\hline Sedation score & LC group $(\mathrm{n}=40)$ & LD group $(\mathrm{n}=40)$ & P Value \\
\hline 1 & 18 & 9 & 0.037 \\
\hline 2 & 14 & 20 & 0.187 \\
\hline 3 & 8 & 11 & 0.471 \\
\hline 4 & 0 & 0 & \\
\hline 5 & 0 & 0 & \\
\hline
\end{tabular}

Table -4 Comparisons of post op block characteristics

\begin{tabular}{|l|c|c|c|}
\hline Post op block characteristics & LC group $(\mathrm{n}=40)$ & LD group $(\mathrm{n}=40)$ & P Value \\
\hline Mean time to two segment regression (mins) & $135.5 \pm 9.8$ & $146.46 \pm 8.5$ & 0.0002 \\
\hline Mean time to sensory regression at S 1(mins) & $285.18 \pm 34.65$ & $345.54 \pm 35.84$ & 0.0001 \\
\hline Mean time to regression to bromage 1(mins) & $251.22 \pm 28.26$ & $284.52 \pm 25.44$ & 0.0001 \\
\hline Time to first rescue top up(mins) & $319.18 \pm 24.81$ & $355.66 \pm 25.8$ & 0.0001 \\
\hline
\end{tabular}

Table 5 -comparison of side effects in intra and post operative period.

\begin{tabular}{|l|c|c|}
\hline Side effect & LC group $(\mathrm{n}=40)$ & LD group $(\mathrm{n}=40)$ \\
\hline Nausea & 5 & 4 \\
\hline Vomiting & 1 & 2 \\
\hline Shivering & 3 & 3 \\
\hline Headache & 0 & 1 \\
\hline Dizziness & 0 & 0 \\
\hline Dry mouth & 1 & 1 \\
\hline Respiratory depression & 0 & 0 \\
\hline
\end{tabular}

\section{Discussion}

Nowadays, a lot of adjuvants are used with local anesthetics in the epidural anesthesia. Primary aim of these adjuvants is to fasten and prolong the sensory and motor block and produce more sedation, analgesia and patient satisfaction without any side effect. The pharmacologic properties of $\alpha-2$ agonists like clonidine and dexmedetomidine have been used extensively in various routes.
Epidural administration of these drugs is associated with sedation, analgesia, anxiolysis, hypnosis and sympatholysis. ${ }^{[8]}$ Clonidine has been used as adjuvant to local anaesthetics successfully over the last few decade. Introduction of dexmedetomidine has raised question about use of clonidine. The faster onset of action, and prolonged duration of analgesia in the postoperative period, makes these agents a very 
effective adjuvant to local anaesthetics in regional anaesthesia. In this study, clonidine was compared with dexmedetomidine as adjuvant to levobupivacaine in epidural anaesthesia. This study was the first study to compare the analgesic and sedative efficacy when clonidine and dexmedetomidine were used as adjuvants to levobupivacaine in epidural anesthesia. The demographic profile of our patients was comparable with respect to mean age, sex, height, body weight, body mass index, ASA status and duration of Surgery.

In our study levobupivacaine - dexmedetomidine combine produced earlier onset of epidural block, prolonged duration of sensory block and more sedation in comparison to levobupivacaineclonidine combine which was statistically significant. There was no statistical difference in haemodynamic parameters in both groups. Studies were there in which either clonidine or dexmedetomidine were used as adjuvant to epidural levobupivacaine. No study had compared clonidine and dexmedetomidine using as adjuvant to epidural levobupivacaine.

Disma et al in their study found that clonidine produced a local anaesthetic sparing effect with a dose dependent decrease in ED 50 of levobupivacaine for caudal anaesthesia. In addition, there was a dose dependent prolongation of postoperative analgesia following lower abdominal surgery in children. A dose of $2 \mu \mathrm{g} \mathrm{kg}$ of clonidine provides the optimum balance between improved analgesia and minimal side effects ${ }^{[10]}$.

Wallet et al in their study found that the addition of clonidine to epidural levobupivacaine and sufentanil for patient controlled epidural analgesia in labour improved analgesia, reduced the supplementation rate and reduced pruritus. Blood pressure was significantly lower in the clonidine group over time but without clinical consequence. [11]

Milligan et al opined that, in patients undergoing total hip replacement, the addition of the alpha(2)adrenergic agonist clonidine to epidural infusions of levobupivacaine significantly improved postoperative analgesia ${ }^{[12]}$.

Akin et al in their study found that caudal clonidine prolonged the duration of analgesia produced by caudal levobupivacaine without causing significant side effects and this was because of a spinal mode of action ${ }^{[13]}$.

Mahran et al opined that both clonidine and fentanyl can be used as effective additive to epidural levobupivacaine for postoperative analgesia after radical cystectomy with no significant difference between them in vital signs, analgesic, sedative effects and safety profile ${ }^{[14]}$. Our study also found similar findings using clonidine as adjuvant to epidural levobupiv-acaine

Manal et al in a comparative study of epidural morphine and epidural dexmedetomidine used as adjuvant to levobupivacaine in major abdominal surgery, found that dexmedetomidine was a good alternative to morphine as an adjuvant to levobupivacaine in epidural anaesthesia in major abdominal surgeries ${ }^{[15]}$. Zeng XZ et al in their study found that low-dose epidural dexmedetomidine improved thoracic epidural anaesthesia for nephrectomy. Sensory and motor blockade duration was longer in the dexemedetomidine group than in the control group. The muscle relaxation score were significantly higher in the dexemedetomidine group compared with the control group. Pain score and analgesic requirement was lower in dexemedetomidine group ${ }^{[16]}$. Ahmed Sobhy Basuni et al used dexmedetomidine as supplement to low-dose levobupivacaine in spinal anaesthesia for knee arthroscopy. They opined that dexmedetomidine was a good alternative to fentanyl for supplementation with low-dose levobupivacaine in spinal anaesthesia for knee arthroscopy ${ }^{[17]}$. Aliye Esmaoglu et al concluded that intrathecal dexmedetomidine addition to levobupivacaine for spinal anaesthesia shortens sensory and motor block onset time and prolongs block duration without any significant adverse effects ${ }^{[18]}$. Our study found similar findings using dexmedetomidine as adjuvant to epidural levobupivacaine. 
A.M. El-Hennawy et al studied the effect of adding clonidine or dexmedetomidine to bupivacaine in caudal block in children. They found that addition of dexmedetomidine or clonidine to caudal bupivacaine significantly plolonged analgesia in children undergoing lower abdominal surgeries with no significant advantage of dexmedetomidine over clonidine and without an increase in incidence of side-effects ${ }^{[19]}$.

Al-Mustafa et al. used dexmedetomidine as an intrathecal adjuvant to bupivcaine and found that its effect was dose-dependent and that its use accelerated the onset of sensory block to reach T10 dermatome.

Bajwa et al showed in their study that dexmedetomidine was a better adjuvant than clonidine in epidural ropivacaine anesthesia for patient comfort, superior sedative and anxiolytic properties, intra-operative and postoperative analgesia. [21]

$\mathrm{Wu} \mathrm{H}-\mathrm{H}$ et al in a retrospective study opined that neuraxial dexmedetomidine was a favorable adjuvant to local anaesthetics which provides better and longer analgesia. Neuraxial dexmedetomidine was associated with good sedation scores and lower analgesic requirements and stable into-operative hemodynamics. [22] Crews et al. found in their study that the use of continuous levobupoivacaine in addition to morphine via a thoracic epidural catheter produced a excellent segmental sensory block and analgesia. ${ }^{[23]}$ All the above studies showed that dexmedetomidine was a better adjuvant to levobupivacaine in epidural anaesthesia. It provided earlier onset and prolonged sensory block. Patient comfort, satisfaction and anxiolysis was better when dexmedetomidine was used as adjuvant to levobupivacaine in epidural route.

\section{Conclusion}

Use of dexmedetomidine as an adjuvant to levobupivacaine was a good alternative to other adjuvants like clonidine, morphine and other opioids in epidural anaesthesia. Both clonidine and dexmedetomidine provided adequate sensory, motor block and their side effects were well tolerated by the patients but dexmedetomidine had an edge over clonidine as adjuvant when used with levobupivacaine in epidural anaesthesia in infraumbilical surgery.

\section{Source of support-nil \\ Conflict of interest-none}

\section{References}

1. Tziavrangos E, Schug SA. Regional anaesthesia and perioperative outcome. Current opinion in anaesthesiology 2006 ; 19:521-525

2. Becker DE, Reed KL.Local anesthetics: review of pharmacological considerations. Anesthesia progress 2012;59:90-101.

3. Ulke ZS, Senturk M. Non-analgesic effects of thoracic epidural anesthesia. Agriculture 2007;19:6-12.

4. Huang Y, Pryor M. Mather L, Veering B. Cardiovascular and central nervous system effects of intravenous levobupivacaine and bupivacine in sheep. Anesth Analg 1998;86:797-804.

5. Bardsley H, Gristwood R. Baker H, et al. A comparision of the cardiovascular effects of levobupivacaine and racbupivacaine following intravenous administration to healthy volunteers. Brint J. Clin Pharmacol 1998; 46:245-9.

6. Kamibayashi T, Maze M. Clinical uses of alpha-2 adrenergic agonists. Anaesthesiology 2000;93:1345-9.

7. Scafati A. Analgesia and alpha agonists 2 Medens Rev 2004;4:7.

8. Mauro VA, Brandao ST. Clonidine and dexmedetomidine through epidural route for postoperative analgesia and sedation in a cholecystectomy. Rev bras Anestesiol 2004;4:1-10.

9. Kanazi GE, Aouad MT, Jabbour Khoury SL, et al. Effect of low dose dexmedetomidine or clonidine on the characteristics of bupivacaine spinal block. Acta Anesthesiol scand 2006;50:222-7. 
10. Disma N, Frawley G, Mameli L. Effect of epidural clonidine on minimum local anesthetic concentration (ED50) of levobupivacaine for caudal block in children. Paediatr Anaesth. 2011 Feb;21 (2):128-35.

11. Wallet F, Clement JH, Bouret C. Effectts of a continuous low-dose clonidine epidural regimen on pain, satisfaction and adverse events during labour: a randomized, double-blind, placebo-controlled trial. Eur J Anaesthesiol. 2010 May; 27(5): 441-7.

12. Milligan KR, Convery PN, Weir P. The efficacy and safety of epidural infusions of levobupivacaine with and without clonidine for postoperative pain relief in patients undergoing total hip replacement. Anesth Analg. 2000 Aug; 91(2):393-7.

13. Akin A, Ocalan S, Esmaglu A. The effects of caudal or intravenous clonidine on postoperative analgesia produced by caudal levobupivacaine in children. Pediatric anesthesia 2010;20:350-355.

14. Mahran E. Ibrahim W. Is the combination of epidural clonidine- levobupivacaine has same analgesic efficacy and safety as the combination Fentanyl - levobupivacaine after radical cystectomy. Egyptian journal of anaesthesia 2014 April; 30(2): 143-147.

15. Manal M. Kamal, Sahar M. Talaat Comparative study of epidural morphine and epidural dexmedetomidine used as adjuvant to levobupivacaine in major abdominal surgery Egyptian Journal of Anaesthesia. 2014 April; 30( 2):137-141.

16. Zeng XZ; Xu YM, CuiXG. Low-dose epidural dexmedetomidine improves thoracic epidural anaesthesia for nephrectomy Anaesthesia And Intensive Care 2014 Mar;. 42(2): 185-90.

17. Ahmed Sobhy Basuni, Hoda Alsaid Ahmed Ezz. Dexmedetomidine as supplement to low-dose levobupivacaine in spinal anaesthesia for knee arthroscopy
Egyptian Journal of Anaesthesia 2014 April;30( 2): 149-153.

18. Aliye Esmaoglul, Sumeyra Turk ,Adnan Bayram, Aynur Akin,. The effects of Dexmedetomidine Added to Spinal Levobupivacaine for Transurethral Endoscopic Surgery, Balkan Med J 2013; 30: $186-90$.

19. M. E-Hennawy, A. M. Abd-Elwahab, A.M. Abd-Elmaksoud,. Addition of clonidine or dexmedetomidine to bupivacaine prolongs caudal analgesia in children. Br. J. Anaesth. 2009;103 (2):268-274.

20. Al-Mustafa MM, Abu-Halaweh SA, Aloweida AS, et al. Effect of dexmedetomidine added to spinal bupivacaine for urological procedures. Saudi Med J. 2009;30:365-70.

21. Bajwa SJS. Bajwa SK, Kaur J, et al Dexmedetomidine and clonidine in epidural anaesthesia: a comparative evaluation. Indian J Anaesthe2011:55(2):116-21

22. Wu H-H, Wang H-T, Jin J-J, et al. Does Dexmedetomidine as a Neuraxial Adjuvant Facilitate Better Anesthesia and Analgesia ? A Systematic Review and Meta-Analysis. PLoS ONE 2014 Mar 9(3):e93114.

23. Crews JC, Hord AH, Denson DD, et al. Comparison of the analgesic efficacy of $0.25 \%$ levobupivacaine combined with $0.005 \%$ morphine, $0.25 \%$ levobupivacaine alone, or $0.005 \%$ morphine, alone for the management of postoperative pain in patients undergoing major abdominal surgery. Anesth Analg 1999;89:150-9. 